\title{
Prediction of Outcome of Sepsis at Surgical ICU: A Prospective Multi-Center Prospective Study
}

\author{
Ahmed M Salem ${ }^{1 *}$, Ahmed E Salem ${ }^{2}$ and Adel F Al Kholy ${ }^{3}$ \\ ${ }^{1}$ Department of Anesthesiology \& ICU, Faculty of Medicine, Benha University, Egypt \\ ${ }^{2}$ Department of Anesthesiology \& ICU, Faculty of Medicine, Tanta University, Egypt \\ ${ }^{3}$ Department of Medical Biochemistry, Faculty of Medicine, Benha University, Egypt
}

Submission: February 01, 2019; Published: March 27, 2019

*Corresponding author: Ahmed M Salem, Department of Anesthesiology \& ICU, Faculty of Medicine, Benha University, Egypt

\begin{abstract}
Objectives: To evaluate predictability of at ICU-admission levels of C-reactive protein (CRP), procalcitonin (PCT), interleukin (IL)-6 and copeptin $(\mathrm{Cp})$ for outcome of patients underwent major surgical resections, admitted to surgical ICU and developed sepsis during ICU stay.

Patients \& Methods: 192 patients developed mild-moderate and 63 patients developed severe sepsis 24-hr after ICU admission. On appearance of early clinical sepsis manifestations, blood samples were obtained for ELISA estimation of studied parameters. Study outcome was defined as the 28-day mortality rate (28-MR) and the best predictor for it.

Results: 28-MR was $22 \%$ and was significantly higher among severe sepsis patients. Severe sepsis patients and non-survivors were significantly older, had higher APACHE II and SOFA scores and serum levels of Cp, IL-6, PCT and CRP than patients had mild-moderate sepsis and survivors, respectively. High serum Cp level was the highly significant independent predictor for both sepsis severity and mortality, while serum PCT was significant predictor for sepsis severity. Serum Cp levels at cutoff points of $\geq 55.2 \mathrm{ng} / \mathrm{ml}$ and $\geq 94.6 \mathrm{ng} / \mathrm{ml}$ could predict progressively increasing hazard of development of severe sepsis and mortality, respectively.
\end{abstract}

Conclusion: Elevated serum Cp could fulfill the requirements for ideal early biomarker for diagnosis and prognosis of sepsis patients especially at the assumed cutoff points. Estimation of serum Cp and PCT in conjunction with clinical scoring could complementary act to approach highest diagnostic and prognostic yield.

Keywords: Surgical ICU sepsis; 28-day mortality rate; prognostic predictors; Co peptin; Procalcitonin

\section{Introduction}

Arginine vasopressin (AVP) is a 9-amino acid peptide synthesized by magnocellular neurons of the hypothalamus [1]. The released VAP is then stored in posterior pituitary gland [2] to be released following different stimuli especially change in plasma osmolality and hypovolemia [3] and various stressors such as hypoxia, acidosis, severe infections and different types of shock [4]. Reliable measurement of AVP is hindered by several factors; its short half-life in serum, its instability in withdrawn blood samples and over $90 \%$ of AVP is tightly bound to platelets [5]. Copeptin (Cp), a 39-aminoacid glycopeptide, is the $\mathrm{COOH}$-terminal portion of the precursor pre-pro-vasopressin termed CTproAVP [6]. Activation of the AVP system stimulates $\mathrm{Cp}$ secretion into the circulation from the posterior pituitary gland in equimolar amounts with AVP [7]. Therefore, Cp directly reflects AVP concentration and can be used as a surrogate biomarker of AVP secretion [8].

The prevalence of sepsis continues to increase, and the sepsis total mortality is growing due to increased morbidity, so sepsis should be considered as an emergency [9]. The Third International Consensus Definitions Task Force defined sepsis as a life-threatening organ dysfunction due to dysregulated host response to infection [10], so its early recognition remains a fundamental challenge in clinical practice [11]. However, the performance of sepsis clinical criteria and scores is unknown [10].

These data indicated the need for an early marker for effects of sepsis that may endanger patient's life. Thus, this study tried to evaluate the predictability of at ICU-admission levels of C-reactive protein (CRP), procalcitonin (PCT) and interleukin (IL)-6 as primary phase reactant and $\mathrm{Cp}$ for outcome of patients underwent major surgical resections, admitted to ICU for cardiopulmonary support and developed infectious complications during ICU stay.

\section{Hypothesis}

The current study supposed that early changes in serum levels of primary phase reactants and copeptin could predict the outcome of patients developed sepsis after admission to ICU. 


\section{Design}

Prospective comparative multi-center observational study

\section{Setting}

ICU centers in University Hospitals, and multiple private hospitals in Benha and Tanta in conjunction with Benha Faculty of Medicine, Egypt

\section{Patients \& Methods}

The study protocol was approved by the Local Ethical Committees and the nearest relative of patients signed written fully informed consents according to the declaration of Helsinki. All patients developed sepsis within the $1^{\text {st }} 24$-hr of ICU admission are eligible for evaluation. Exclusion criteria included development of sepsis prior to ICU admission, maintenance on immune depressant therapy for any indication, severe hemorrhagic shock, tissue hypoperfusion diagnosed if Systolic Blood Pressure (SBP) was $\leq 90 \mathrm{mmHg}$, Urinary Output (UOP) $<0.5 \mathrm{ml} / \mathrm{kg} / \mathrm{min}$ for $>2 \mathrm{~h}$, increased Heart Rate (HR) by $\geq 10 \%$ from baseline, skin mottling and/or hyperlactatemia ( $>2 \mathrm{mmol} / \mathrm{L}$ ) [12], pregnancy, children and adulthoods younger than 18 years and patients who were not expected to survive were also excluded from the study.

Collected at enrollment data included demographic characteristics, including age, sex, Body Mass Index (BMI) data, acute physiology and chronic health evaluation II score (APACHE II) [13], global hemodynamic parameters, arterial and central venous blood gas analysis and pH were obtained simultaneously. Impact of disease on body organs was evaluated using the Sequential Organ Failure Assessment (SOFA) scores [14] at time of insertion of the central venous catheter.

Sepsis was diagnosed depending on the presence of at least two of the four Systemic Inflammatory Response Syndrome (SIRS) criteria's and fulfilled the requirements for either severe sepsis or septic shock as documented by Yussof et al. [15]. Patients were managed according to the Surviving Sepsis Campaign guidelines [16] with hemodynamic support aiming to achieve the following: Central Venous Pressure (CVP) of 8-12mmHg; Mean Arterial Pressure $(\mathrm{MAP})>65 \mathrm{mmHg}$ and $\mathrm{UOP}>0.5 \mathrm{ml} / \mathrm{kg}$ of body weight.

\section{Blood sampling}

At time of appearance of early clinical manifestations of sepsis, $5 \mathrm{ml}$ blood sample was withdrawn under complete aseptic conditions, allowed to clot and then centrifuged at 3000rpm for 10 minutes to separate serum that was collected in sterile Eppindorff tube and stores at $-80 \mathrm{oC}$ till be assayed. Blood samples were collected and numbered by an assistant who was blinded about diagnosis.

\section{Laboratory investigations}

Serum levels of CRP, PCT, IL-6 and Cp were measured using enzyme linked immunosorbent assay (ELISA) kits according to the manufacturer's instructions and were read using a 96 well microplate ELISA reader (Dynatech. MR 7000) a. Human CRP was measured with the Enzyme Linked Immunoassay (ELISA) kit () by quantitative sandwich enzyme immunoassay technique [17].

b. Human PCT was measured with the Enzyme Linked Immunoassay (ELISA) kit () by quantitative sandwich enzyme immunoassay technique [18].

c. Human IL-6 was measured with the Enzyme Linked Immunoassay (ELISA) kit (catalogue no. IL631-k01, Eagle Biosciences, Inc., USA) by quantitative sandwich enzyme immunoassay technique [19].

d. Human Cp was measured with the Enzyme Linked Immuno Assay (ELISA) kit () by quantitative sandwich enzyme immunoassay technique [20].

\section{Study outcome}

Study outcome is defined as the mortality rate throughout 28 days (28-MR) of management and follow-up after development of sepsis and the best predictor for it.

\section{Study power calculation}

Review of literature showed that the overall MR of surgical patients not requiring ICU admission is $18.2 \%$ [21] and among those admitted to ICU is 28.7 [22] to defined the predictability of estimated parameters for MR among surgical patients admitted to ICU and developed sepsis and to get study power of $80 \%$ with $\alpha$ value of 0.05 and $\beta$ value of 0.2 , sample size was calculated to be 254 patients.

\section{Statistical analysis}

Obtained data were presented as mean \pm SD, numbers and percentages. Data were analyzed using One-way ANOVA Test. Possible relationships were investigated using Pearson linear regression analysis. Sensitivity \& specificity of estimated parameters as predictors for 28-MR were evaluated using the Receiver Operating Characteristic (ROC) curve analysis judged by the Area Under Curve (AUC) that was compared versus null hypothesis that AUC=0.5. Kaplan-Meier regression analysis was used to determine a cutoff point for serum Cp above which 28-MR increases. Statistical analysis was conducted using the IBM SPSS (Version 23, 2015 ) for Windows statistical package. P value $<0.05$ was considered statistically significant.

\section{Results}

Throughout 5-year case collection period 287 cases of those admitted to surgical ICU were eligible for evaluation. Unfortunately, 15 patients required emergency $2^{\text {nd }}$ look surgery for causes other than sepsis and were excluded from the study and 17 patients were excluded for not fulfilling the study inclusion criteria; thus 255 patients were enrolled in the study. During ICU stay, 63 patients developed severe sepsis (24.7\%); twenty of them were progressed to septic shock, while 192 patients had mild-moderate sepsis (Figure 1). 


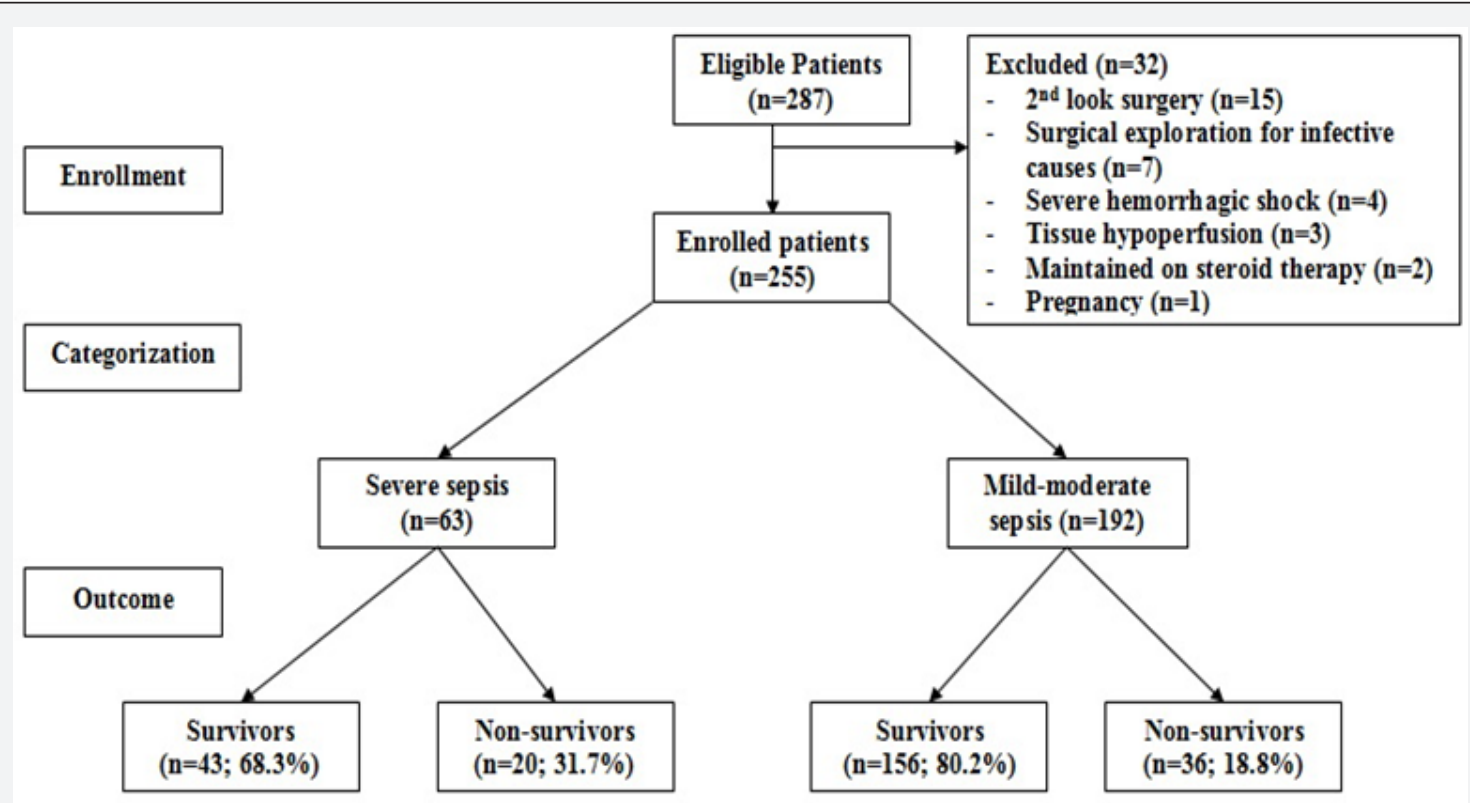

Figure 1: Folw chart of the study.

Patients who developed severe sepsis were significantly older and obese and had higher APACHE II and SOFA scores. Also, at ICU admission MAP, CVP and UOP were significantly lower in

severe sepsis patients. Laboratory variables estimated at time of development of sepsis were significantly higher in severe sepsis patients than patients developed mild-moderate sepsis (Table 1).

Table 1: Clinical and laboratory data of studied patients categorized according to severity of sepsis.

\begin{tabular}{|c|c|c|c|c|}
\hline & & Mild-Moderate Sepsis (n=192) & Severe Sepsis $(n=63)$ & P Value \\
\hline \multicolumn{2}{|c|}{ Age (years) } & $53.2 \pm 4.3$ & $56 \pm 4.8$ & $<0.001$ \\
\hline \multicolumn{2}{|c|}{ Sex; M:F } & $125: 67$ & $35: 28$ & 0.224 \\
\hline \multicolumn{2}{|c|}{ Body mass index $\left(\mathrm{kg} / \mathrm{m}^{2}\right)$} & $29.5 \pm 2.3$ & $31 \pm 2.6$ & $<0.001$ \\
\hline \multicolumn{2}{|c|}{ APACHE II score } & $22.1 \pm 2.9$ & $24 \pm 4$ & $<0.001$ \\
\hline \multicolumn{2}{|c|}{ SOFA score } & $9.6 \pm 1.9$ & $10.9 \pm 2.4$ & $<0.001$ \\
\hline \multicolumn{2}{|c|}{ MAP (mmHg) } & $64.3 \pm 4.4$ & $63 \pm 4.3$ & 0.041 \\
\hline \multicolumn{2}{|c|}{ CVP (mmHg) } & $8.2 \pm 0.95$ & $7.9 \pm 0.9$ & 0.022 \\
\hline \multicolumn{2}{|c|}{ UOP (ml/hr) } & $0.56 \pm 0.16$ & $0.48 \pm 0.13$ & $<0.001$ \\
\hline \multirow{4}{*}{ Laboratory data } & $\mathrm{CRP}(\mathrm{ng} / \mathrm{ml})$ & $110.3 \pm 32.2$ & $119.9 \pm 42.5$ & $<0.001$ \\
\hline & $\mathrm{IL}-6$ (ng/ml) & $91.4 \pm 35.1$ & $134.1 \pm 62.7$ & $<0.001$ \\
\hline & PCT (ng/ml) & $2.21 \pm 1.65$ & $4.1 \pm 2.2$ & $<0.001$ \\
\hline & $\mathrm{Cp}(\mathrm{ng} / \mathrm{ml})$ & $43.14 \pm 23.8$ & $75.5 \pm 22$ & $<0.001$ \\
\hline
\end{tabular}

During 28-days after appearance of sepsis manifestations, 56 patients died for sepsis-related mortality rate of $22 \%$. Non-survivors were 20 severe sepsis patients $(31.7 \%)$ and 36 patients had mild-moderate sepsis $(18.8 \%)$ with significantly $(\mathrm{p}=0.031)$ higher mortality rate among patients had severe sepsis. Non-survivors were significantly older and had significantly higher APACHE II and SOFA scores, significantly lower MAP, but significantly higher serum levels of CRP, IL-6, PCT and CP than survivors. However, non-survivors were non-significantly obese and had non-significantly lower CVP and UOP than survivors (Table 2). 
Table 2: Clinical and laboratory data of studied patients categorized according to survival outcome.

\begin{tabular}{|c|c|c|c|c|}
\hline & & Survivors $(n=174)$ & Non-Survivors $(n=56)$ & $P$ Value \\
\hline \multicolumn{2}{|c|}{ Age (years) } & $53.1 \pm 4$ & $55 \pm 5.1$ & 0.011 \\
\hline \multicolumn{2}{|c|}{ Sex; M:F } & $128: 71$ & $33: 23$ & 0.506 \\
\hline \multicolumn{2}{|c|}{ Body mass index $\left(\mathrm{kg} / \mathrm{m}^{2}\right)$} & $29.6 \pm 2.2$ & $30 \pm 2.5$ & 0.411 \\
\hline \multicolumn{2}{|c|}{ APACHE II score } & $22 \pm 2.9$ & $23.5 \pm 4$ & 0.005 \\
\hline \multicolumn{2}{|c|}{ SOFA score } & $9.6 \pm 1.8$ & $10.5 \pm 2.2$ & 0.005 \\
\hline \multicolumn{2}{|c|}{ MAP (mmHg) } & $64.4 \pm 4.3$ & $62.4 \pm 5.2$ & 0.006 \\
\hline \multicolumn{2}{|c|}{ CVP (mmHg) } & $8.2 \pm 1$ & $8 \pm 0.9$ & 0.351 \\
\hline \multicolumn{2}{|c|}{ UOP $(\mathrm{ml} / \mathrm{hr})$} & $0.55 \pm 0.16$ & $0.54 \pm 0.15$ & 0.885 \\
\hline \multirow{4}{*}{ Laboratory data } & $\mathrm{CRP}(\mathrm{mg} / \mathrm{ml})$ & $102.6 \pm 34.5$ & $114.2 \pm 39.9$ & 0.044 \\
\hline & IL-6 (mg/ml) & $97.3 \pm 43.9$ & $118.3 \pm 54.6$ & 0.006 \\
\hline & PCT (mg/ml) & $2.48 \pm 1.76$ & $3.36 \pm 2.5$ & 0.005 \\
\hline & $\mathrm{Cp}(\mathrm{mg} / \mathrm{ml})$ & $47.55 \pm 25.9$ & $63.84 \pm 28.2$ & 0.0002 \\
\hline
\end{tabular}

Regression analysis for at ICU admission patients' data and laboratory finding defined old age, high APACHE II score and high serum levels of CRP, IL-6, PCT and Cp as the significant predictors for possibility of development of severe sepsis. Verification of these predictors using ROC curve analysis defined high serum $\mathrm{Cp}$ level at time of appearance of sepsis manifestations as the highly significant sensitive predictor for possibility of progress of sepsis to severe sepsis, followed by high serum PCT, IL-6, old age, high APACHE II score and high serum CRP, in descending order of significance (Table 3, Figure 2).

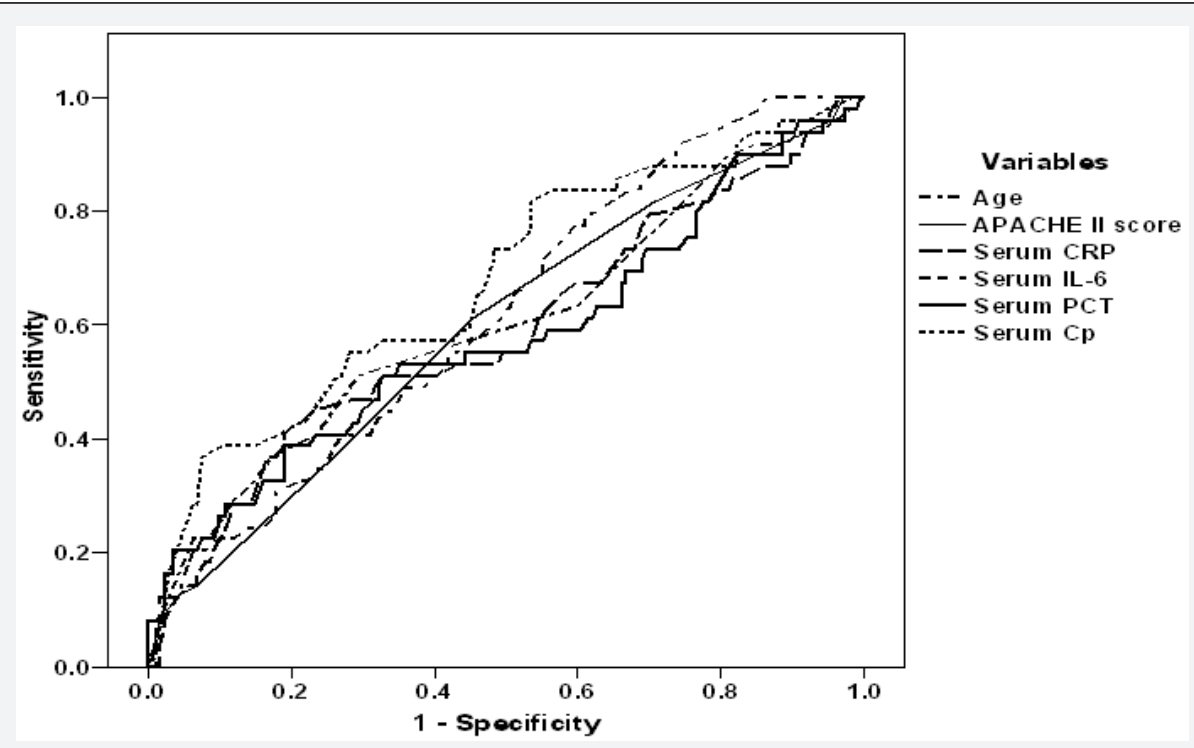

Figure 2: ROC curve analysis for evaluated variables as predictors for possibility of development of severe sepsis.

Table 3: Regression and ROC curve analyses for predictors of severe sepsis and mortality among ICU patients who developed sepsis.

\begin{tabular}{|c|c|c|c|c|c|c|}
\hline \multirow{3}{*}{ Outcome } & \multirow{3}{*}{ Variables } & \multicolumn{2}{|c|}{ Regression Analysis } & \multicolumn{3}{|c|}{ ROC Curve Analysis } \\
\cline { 3 - 7 } & & $\boldsymbol{\beta}$ & Sig. & AUC \pm \pm SE) & Sig. & $\mathbf{9 5 \%}$ CI \\
\hline \multirow{5}{*}{ Severe sepsis } & Age & 0.110 & 0.033 & $0.312( \pm 0.045)$ & $<0.001$ & $0.224-0.400$ \\
\cline { 2 - 8 } & APACHE II score & 0.186 & $<0.001$ & $0.326( \pm 0.041)$ & $<0.001$ & $0.245-0.407$ \\
\cline { 2 - 8 } & Serum CRP & 0.168 & 0.001 & $0.363( \pm 0.049)$ & 0.002 & $0.268-0.459$ \\
\cline { 2 - 8 } & Serum IL-6 & 0.317 & $<0.001$ & $0.291( \pm 0.044)$ & $<0.001$ & $0.205-0.376$ \\
\cline { 2 - 8 } & Serum PCT & 0.205 & $<0.001$ & $0.256( \pm 0.041)$ & $<0.001$ & $0.176-0.336$ \\
\cline { 2 - 8 } & Serum Cp & 0.336 & $<0.001$ & $0.162( \pm 0.032)$ & $<0.001$ & $0.100-0.224$ \\
\hline
\end{tabular}


Journal of Anesthesia \& Intensive Care Medicine

\begin{tabular}{|c|c|c|c|c|c|c|}
\hline \multirow{7}{*}{ Mortality } & Age & -0.187 & 0.009 & $0.604( \pm 0.049)$ & 0.026 & $0.508-0.700$ \\
\cline { 2 - 8 } & SOFA score & -0.137 & 0.028 & $0.596( \pm 0.046)$ & 0.039 & $0.506-0.687$ \\
\cline { 2 - 8 } & Serum CRP & -0.161 & 0.015 & $0.589( \pm 0.049)$ & 0.058 & $0.492-0.685$ \\
\cline { 2 - 8 } & Serum IL-6 & -0.269 & $<0.001$ & $0.621( \pm 0.043)$ & 0.009 & $0.537-0.706$ \\
\cline { 2 - 8 } & Serum PCT & -0.158 & 0.012 & $0.581( \pm 0.050)$ & 0.084 & $0.482-0.679$ \\
\cline { 2 - 8 } & Serum Cp & -0.243 & $<0.001$ & $0.674( \pm 0.045)$ & $<0.001$ & $0.586-0.763$ \\
\hline
\end{tabular}

For prediction of mortality among patients developed sepsis, Regression analysis defined old age, high SOFA score and high serum levels of CRP, IL-6, PCT and Cp as the significant negative predictors for survival. Verification of these predictors using ROC

curve analysis defined high serum $\mathrm{Cp}$ level at time of appearance of sepsis manifestations as the highly significant specific predictor for mortality, followed by high serum IL-6, old age and high SOFA score, in descending order of significance (Table 3, Figure 3).

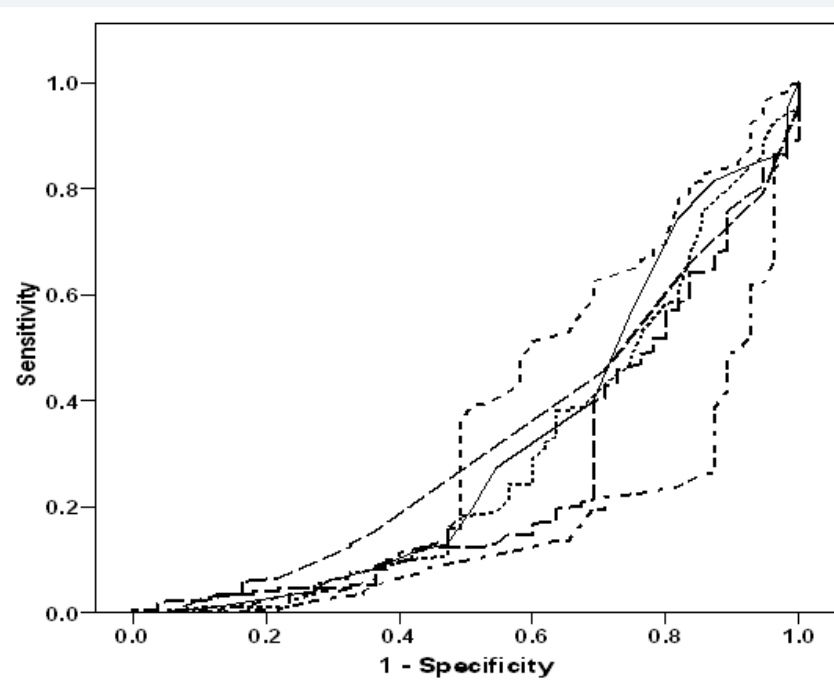

\section{Variables \\ - Age \\ - SOFA score \\ - - Serum CRP \\ -..- Serum IL-6 \\ $--\operatorname{ser}(0)$ \\ - - Serum Cp}

Figure 3: ROC curve analysis for evaluated variables as predictors for mortality.

Kaplan-Meier regression analysis for serum Cp levels of studied patients defined median value at $55.2 \pm 4.33 \mathrm{ng} / \mathrm{ml}(95 \% \mathrm{CI}$ : 46.7-63.7) as cutoff point above which the hazard of develop- ment of severe sepsis increased progressively (Figure 4) and at 94.6 $\pm 1.07 \mathrm{ng} / \mathrm{ml}$ (95\% CI: 92.5-96.7) as cutoff point above which the hazard of death increased progressively (Figure 5).

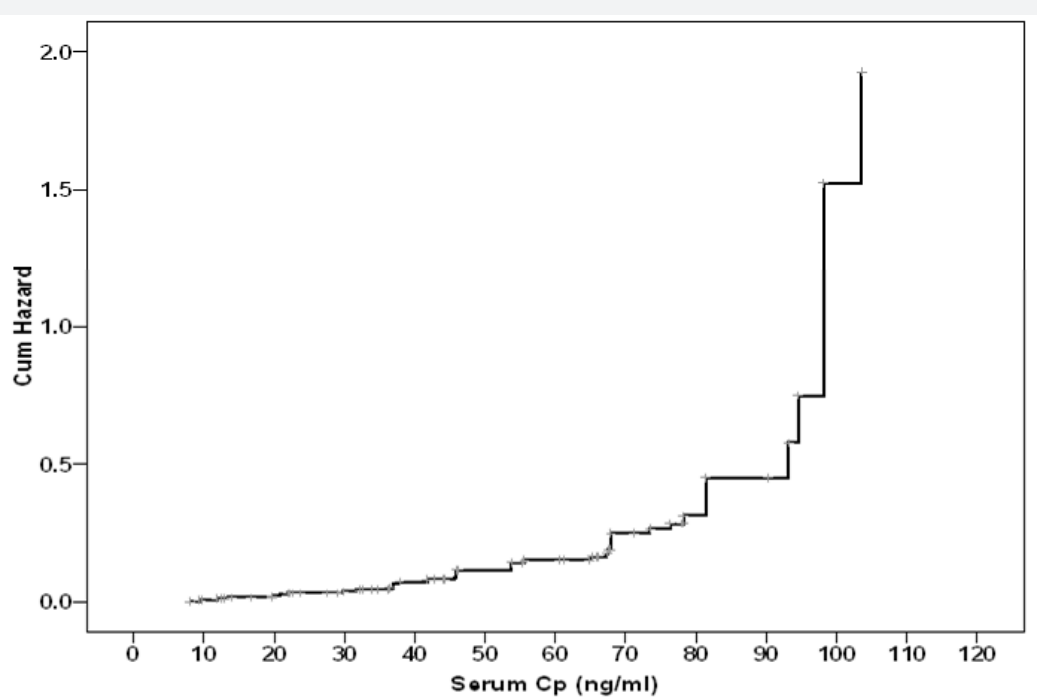

Figure 4: Kaplan-Meier Regression curve showed progressive increase of cumulative hazard for development of severe sepsis at cutoff point of $\geq 55.2 \mathrm{ng} / \mathrm{ml}$. 


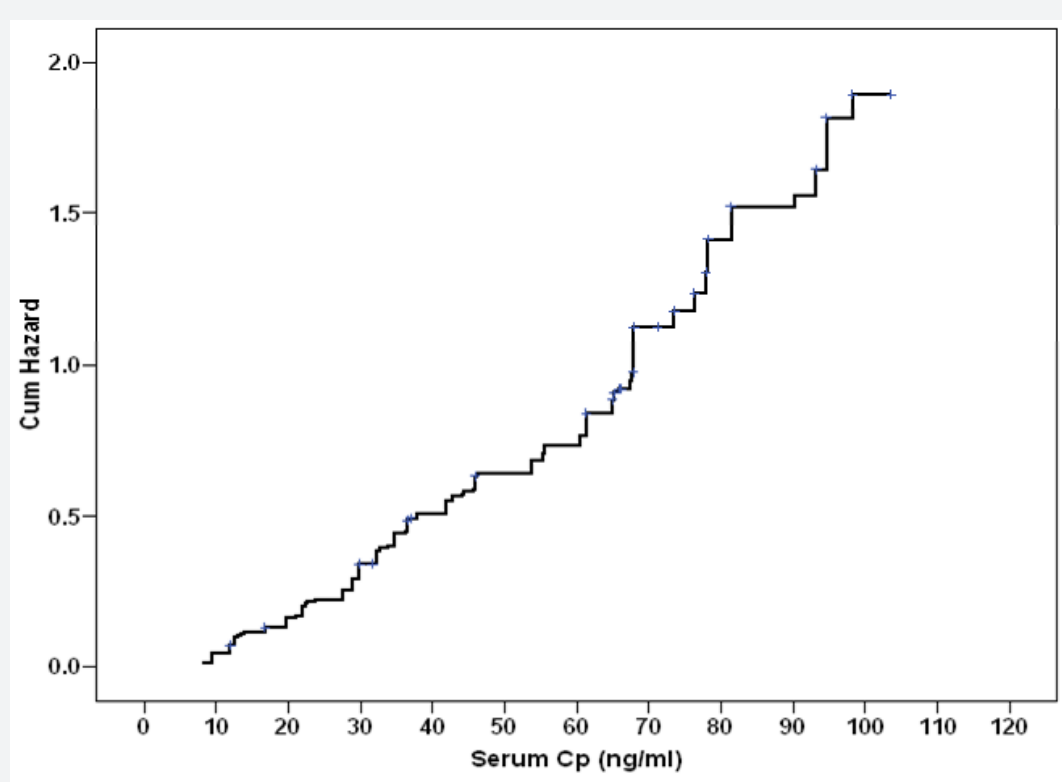

Figure 5: Kaplan-Meier Regression curve showed progressive increase of cumulative hazard for development of severe sepsis at cutoff point of $\geq 94.6 \mathrm{ng} / \mathrm{ml}$.

\section{Discussion}

Throughout 5-year duration of study, 255 of patients admitted to surgical ICU for varied indications developed sepsis 24-hr after ICU admission; such observation goes in hand with Sakr et al. [23] who reported an incidence of sepsis during the ICU stay of $11.4 \%$ and found sepsis was observed within 48 hours after ICU admission in 50.9\% while $49.1 \%$ developed ICU-acquired sepsis. Out of the currently studied patients, 63 patients had severe sepsis (24.7\%), a figure which is better that that reported by Zhou et al. [22] who found 37.3/100 ICU admissions were diagnosed with severe sepsis or septic shock.

The current study reported a 28-day mortality rate (28-MR) of $22 \%$ among these patients who developed sepsis during ICU stay; in line with this figure Yoo et al. [24] and Badia et al. [25] reported a 28-MR of 19 and 19.6\%, respectively. However, the reported 28-MR was lower than the rates of $41.3 \%, 28.7 \%$ and $29 \%$ which had been reported by Zhou et al. [22], Sakr et al. [23] \& Yokota et al., [26], respectively.

The currently reported percentage of non-survivors was significantly higher among patients who had severe sepsis and septic shock than patients who developed mild-moderate sepsis $(31.7 \%$ vs. $18.8 \%$ ). Similarly, Heldens et al. [27] reported MR of $17 \%$ and $37 \%$ in patients diagnosed with sepsis and septic shock, respectively.

Severe sepsis patients and non-survivors were significantly older and had higher APACHE II and SOFA scores with significantly lower MAP, CVP and UOP at time of ICU admission. Moreover, statistical analyses defined high at admission APACHE II and SOFA scores as predictors for possibility of developing severe sepsis and/or mortality, respectively. Multiple recent studies assured that among variables registered on day 1, APACHE II and SOFA scores were independently associated with sepsis severity and 28-MR [28-30].

Moreover, severe sepsis patients and non-survivors showed significantly higher serum levels of Cp, IL-6, PCT and CRP than patients had mild-moderate sepsis and survivors, respectively. Statistical analyses defined high serum $\mathrm{Cp}$ levels as the most the highly significant independent predictor for both sepsis severity and mortality, followed by high serum IL-6, while serum PCT was significant predictor for severity of sepsis. All of the three markers showed superior diagnostic validity than clinical data and scores.

In line with these data, Jiang et al. [31] found plasma Cp, CRP and PCT concentrations were positively correlated with APACHE II score in patients with sepsis, and reflected disease severity, while Ameen et al. [32] reported that at admission serum Cp and blood lactate levels are significant predictors for mortality of septic patients. Also, Huang et al. [33] documented that APACHE II scores and the levels of serum calprotectin and PCT on postoperative day-1 were the variables significantly associated with sepsis and its severity. Thereafter, Ríos-Toro et al. [34] found the absence of risk factors for infection and decrease of PCT and IL-6 levels from baseline to day- 5 were variables associated to survival in the univariate analysis. Recently, Qiu et al. [35] reported that serum Hepcidin, PCT, IL-6, TNF- $\alpha$, APACHE II, SOFA score and 28-MR all showed an increasing trend with the increase in infection severity in ICU patients. Also, Barre et al. [36] found both IL-6 and monocyte chemotactic protein 1 levels had valuable prognostic discrimination of 30-day and 6-months all-cause mortality compared to PCT, CRP, SOFA and APACHE II score. 
Regarding serum $\mathrm{Cp}$, the obtained results go in hand with Zhang et al. [37], who reported that high baseline Cp levels may provide crucial information for risk stratification in a variety of septic states and were independent predictors of septic shock and 28-MR with AUC of 0.856 and 0.826 , respectively. Also, Battista et al. [38] documented that $\mathrm{Cp}$ can distinguish cases of sepsis from controls and between sepsis and septic shock patients, while PCT could distinguish severe sepsis from septic shock patients.

Regression analysis showed that serum Cp levels at cutoff points of $\geq 55.2 \mathrm{ng} / \mathrm{ml}$ and $\geq 94.6 \mathrm{ng} / \mathrm{ml}$ could predict progressively increasing hazard of development of severe sepsis and mortality, respectively. These findings point to the feasibility of reliance on estimated serum $\mathrm{Cp}$ level at time of appearance of early manifestations of sepsis to predict patients' outcome. Similarly, Dabla et al. [39] reported that $\mathrm{Cp}$ levels are altered in various physiological and pathological conditions indicating its possible diagnostic and prognostic roles in various clinical settings especially in critically ill patients. In line with the validity of $\mathrm{Cp}$ cutoff point for diagnosis and prediction of outcome of septic patients Battista et al. [38] found patients with $\mathrm{Cp}$ concentrations higher $>23.2 \mathrm{pmol} / \mathrm{L}$ at-admission presented higher 30-day mortality.

Recently, in 2018, Koch et al. [40] reported significantly elevated plasma Cp levels in critically ill patients at ICU admission than control levels, and were closely associated with disease severity judged by APACHE-II score, correlated with biomarkers of inflammation and tissue perfusion and could predict short-term and long-term mortality, so concluded that $\mathrm{Cp}$ could be a promising tool for prognostication and management of critically ill patients.

\section{Conclusion}

Development of sepsis after admission to surgical ICU is still a problematic dilemma. Despite of the diagnostic validity of clinical scores, it could not fulfill the best prognostic target for sepsis patients. Early systemic release of primary-phase reactants could be a diagnostic and prognostic tool for sepsis patients even prior to establishment of diagnosis. Elevated serum co-peptin could fulfill the requirements for ideal early biomarker for diagnosis and prognosis of sepsis patients especially at the assumed cutoff points. Combined estimation of serum co-peptin and procalcitonin in conjunction with clinical scoring could complementary act to approach highest diagnostic and prognostic yield. However, wider scale studies are mandatory to assure the validity of the assumed cutoff points for co-peptin.

\section{References}

1. Adukauskiene D, Sirvinskas E, Kevelaitis E (2008) Vasopressin for treatment of hemodynamic disorders. Medicina (Kaunas) 44(2): 167173.

2. Treschan TA, Peters J (2006) The vasopressin system: physiology and clinical strategies. Anesthesiology 105(3): 599-612.

3. Oliver JA, Landry DW (2007) Endogenous and exogenous vasopressin in shock. Curr Opin Crit Care 13(4): 376-382.
4. Mitra JK, Roy J, Sengupta S (2011) Vasopressin: Its current role in anesthetic practice. Indian J Crit Care Med 15(2): 71-77.

5. Jarosz Lesz A, Maruniak-Chudek I (2015) Copeptin - stable C-terminal fragment of pre-provasopressin as a new stress marker in newborns. Postepy Hig Med Dosw (Online) 69: 681-689.

6. Morgenthaler NG, Struck J, Jochberger S, Dünser MW (2008) Copeptin: clinical use of a new biomarker. Trends Endocrinol Metab 19(2): 4349.

7. Asferg CL, Andersen UB, Linneberg A, Goetze JP, Holst JJ, et al. (2018) Copeptin, a surrogate marker for arginine vasopressin secretion, is positively associated with glucagon. Diabet Med.

8. Velho G, Ragot S, El Boustany R, Saulnier PJ, Fraty M, et al. (2018) Plasma copeptin, kidney disease, and risk for cardiovascular morbidity and mortality in two cohorts of type 2 diabetes. Cardiovasc Diabetol 17(1): 110 .

9. Cavrić G, Nassabain K, Prkačin I, Hamp DB (2015) Something about definition and epidemiology of sepsis. Acta Med Croatica 69(3): 125-134.

10. Seymour CW, Liu VX, Iwashyna TJ, Brunkhorst FM, Rea TD, et al. (2016) Assessment of Clinical Criteria for Sepsis: For the Third International Consensus Definitions for Sepsis and Septic Shock (Sepsis-3). JAMA 315(8): 762-774.

11. Horák J, Harazim M, Karvunidis T, Raděj J, Novák I, et al. (2016) Sepsis how to recognize and what to focus on - back to basics in the light of the new definition. Vnitr LekFall 62(7-8): 568-574.

12. Rodriguez A, Lisboa T, Martín Loeches I, Díaz E, Trefler S, et al. (2011) Mortality and regional oxygen saturation index in septic shock patients: a pilot study. J Trauma 70(5): 1145-1152.

13. Knaus WA, Draper EA, Wagner DP, Zimmerman JE (1985) APACHE II: a severity of disease classification system. Crit Care Med 13(10): 818829.

14. Vincent JL, Moreno R, Takala J, Willatts S, De Mendonça A, et al. (1996) The SOFA (Sepsis-related Organ Failure Assessment) score to describe organ dysfunction/failure. On behalf of the Working Group on SepsisRelated Problems of the European Society of Intensive Care Medicine. Intensive Care Med 22(7): 707-710.

15. Yussof SJ, Zakaria MI, Mohamed FL, Bujang MA, Lakshmanan S, et al. (2012) Value of Shock Index in Prognosticating the Short Term Outcome of Death for Patients Presenting With Severe Sepsis and Septic Shock in The Emergency Department. Med J Malaysia 67(4): 406-411.

16. Leone M, Boyadjiev I, Boulos E, Antonini F, Visintini P, et al. (2006) A reappraisal of isoproterenol in goal-directed therapy of septic shock. Shock 26(4): 353-357.

17. Volkova E, Willis JA, Wells JE, Robinson BA, Dachs GU, et al. (2011) Association of angiopoietin-2, C-reactive protein and markers of obesity and insulin resistance with survival outcome in colorectal cancer. Br J Cancer 104(1): 51-59.

18. Uzzan B, Cohen R, Nicolas P, Cucherat M, Perret GY (2006) Procalcitonin as a diagnostic test for sepsis in critically ill adults and after surgery or trauma: a systematic review and meta-analysis. Crit Care Med 34(7): 1996-2003.

19. Gaines Das RE, Poole S (1993) The international standard for interleukin-6. Evaluation in an international collaborative study. J Immunol Methods 160(2): 147-153.

20. Zhang X, Lu XM, Huang LF, Ye H (2012) Copeptin is associated with one-year mortality and functional outcome in patients with acute spontaneous basal ganglia hemorrhage. Peptides 33(2): 336-341. 
21. Elias AC, Matsuo T, Grion CM, Cardoso LT, Verri PH (2012) Incidence and risk factors for sepsis in surgical patients: a cohort study. J Crit Care 27(2): 159-166

22. Zhou J, Qian C, Zhao M, Yu X, Kang Y, et al. (2014) Epidemiology and outcome of severe sepsis and septic shock in intensive care units in mainland China. PLoS One 9(9): e107181.

23. Sakr Y, Elia C, Mascia L, Barberis B, Cardellino S, et al. (2013) Epidemiology and outcome of sepsis syndromes in Italian ICUs: a muticentre, observational cohort study in the region of Piedmont Minerva Anestesiol 79(9): 993-1002.

24. Yoo JW, Lee JR, Jung YK, Choi SH, Son JS, et al. (2015) A combination of early warning score and lactate to predict intensive care unit transfer of inpatients with severe sepsis/septic shock. Korean J Intern Med $30(4): 471-477$

25. Badia M, Iglesias S, Serviá L, Domingo J, Gormaz P (2015) Mortality predictive factors in patients with urinary sepsis associated to upper urinary tract calculi. Med Intensiva 39(5): 290-297.

26. Yokota PK, Marra AR, Martino MD, Victor ES, Durão MS, et al. (2014) Impact of appropriate antimicrobial therapy for patients with severe sepsis and septic shock--a quality improvement study. PLoS One 9(11): e104475.

27. Heldens M, Schout M, Hammond NE, Bass F, Delaney A, et al. (2018) Sepsis incidence and mortality are underestimated in Australian intensive care unit administrative data. Med J Aust 209(6): 255-260.

28. Ruminski CM, Clark MT, Lake DE, Kitzmiller RR, Keim Malpass J, et al. (2018) Impact of predictive analytics based on continuous cardiorespiratory monitoring in a surgical and trauma intensive care unit. J Clin Monit Comput.

29. Ogura T, Nakamura Y, Takahashi K, Nishida K, Kobashi D, et al. (2018) Treatment of patients with sepsis in a closed intensive care unit is associated with improved survival: a nationwide observational study in Japan. J Intensive Care 6: 57.

30. Costa NA, Gut AL, Azevedo PS, Polegato BF, Magalhães ES, et al (2018) Peptidylarginine deiminase 4 concentration, but not PADI4 polymorphisms, is associated with ICU mortality in septic shock patients. J Cell Mol Med 22(10): 4732-4737.
31. Jiang L, Feng B, Gao D, Zhang Y (2015) Plasma concentrations of copeptin, C-reactive protein and procalcitonin are positively correlated with APACHE II scores in patients with sepsis. J Int Med Res 43(2): 188-195.

32. Ameen A, Abdel Rehim M, Shaaban YH (2016) Endocrine and metabolic alterations may underlie mortality of severe sepsis and septic shock patients admitted to ICU. J Egypt Soc Parasitol 46(1): 109-116.

33. Huang L, Li J, Han Y, Zhao S, Zheng Y, et al. (2016) Serum Calprotectin Expression as Diagnostic Marker for Sepsis in Postoperative Intensive Care Unit Patients. J Interferon Cytokine Res 36(10): 607-616.

34. Ríos Toro JJ, Márquez Coello M, García Álvarez JM, Martín Aspas A, Rivera Fernández R, et al. (2017) Soluble membrane receptors, interleukin 6 , procalcitonin and $\mathrm{C}$ reactive protein as prognostic markers in patients with severe sepsis and septic shock. PLoS One 12(4): e0175254

35. Qiu Z, Shen K, Shu M, Xu D, Deng X, et al. (2018) Value of Hepcidin as a diagnostic biomarker of sepsis in critically ill adults. Zhonghua Wei Zhong Bing Ji Jiu Yi Xue 30(7): 652-657.

36. Barre M, Behnes M, Hamed S, Pauly D, Lepiorz D, et al. (2018) Revisiting the prognostic value of monocyte chemotactic protein 1 and interleukin-6 in the sepsis-3 era. J Crit Care 43: 21-28.

37. Zhang Q, Dong G, Zhao X, Wang M, Li CS (2014) Prognostic significance of hypothalamic-pituitary-adrenal axis hormones in early sepsis: a study performed in the emergency department. Intensive Care Med 40(10): 1499-1508.

38. Battista S, Audisio U, Galluzzo C, Maggiorotto M, Masoero M, et al. (2016) Assessment of Diagnostic and Prognostic Role of Copeptin in the Clinical Setting of Sepsis. Biomed Res Int p. 7.

39. Dabla PK, Dabla V, Arora S (2010) Co-peptin: Role as a novel biomarker in clinical practice. Clin Chim Acta 412(1-2): 22-28.

40. Koch A, Yagmur E, Hoss A, Buendgens L, Herbers U, et al. (2018) Clinical relevance of copeptin plasma levels as a biomarker of disease severity and mortality in critically ill patients. J Clin Lab Anal 32(9): e22614.

\begin{tabular}{l} 
Your next submission with Juniper Publishers \\
will reach you the below assets \\
- Quality Editorial service \\
- Swift Peer Review \\
- Reprints availability \\
- E-prints Service \\
- Manuscript Podcast for convenient understanding \\
- Global attainment for your research \\
- Manuscript accessibility in different formats \\
( Pdf, E-pub, Full Text, Audio) \\
- Unceasing customer service \\
Track the below URL for one-step submission \\
https://juniperpublishers.com/online-submission.php \\
\hline
\end{tabular}

